\title{
Preparation of di-boride coatings by electrophoretic deposition in nanoparticle-containing molten inorganic salts
}

\section{Weiliang Jin}

Anhui University of Technology

Saijun Xiao ( $\nabla$ xiaosaijunzj@yahoo.com )

Anhui University of Technology https://orcid.org/0000-0003-0059-9327

Qian Kou

Anhui University of Technology

Desheng Ding

Anhui University of Technology

Jun Zhang

University of Science and Technology Beijing

Xiaohong Fang

Anhui University of Technology

Chuntao Ge

Anhui University of Technology

Cong Zhong

Anhui University of Technology

Hongmin Zhu

Tohoku University

Geir Martin Haarberg

NTNU

\section{Research Article}

Keywords: electrophoretic deposition, molten inorganic salts, di-boride nanoparticles, di-boride coatings

Posted Date: April 23rd, 2021

DOI: https://doi.org/10.21203/rs.3.rs-306473/v2

License: (1) (1) This work is licensed under a Creative Commons Attribution 4.0 International License.

Read Full License 


\title{
Preparation of di-boride coatings by electrophoretic deposition in nanoparticle-containing molten inorganic salts
}

\author{
Weiliang Jin ${ }^{1}$, Saijun Xiao ${ }^{1 *}$, Qian Kou' ${ }^{1}$ Desheng Ding ${ }^{1}$, Jun Zhang ${ }^{2,1}$, Xiaohong Fang ${ }^{1}$, Chuntao Ge ${ }^{1}$, Cong Zhong ${ }^{1}$, \\ Hongmin $\mathrm{Zhu}^{2,3^{*}}$, Geir Martin Haarberg ${ }^{4^{*}}$ \\ 1School of Metallurgy Engineering, Anhui University of Technology, Ma Xiang Road, Yushan District, Maanshan243032, \\ China. \\ 2School of Metallurgical and Ecological Engineering, University of Science and Technology Beijing, Xueyuan Road, \\ Haidian District, Beijing100083, China. \\ 3Department of Metallurgy, Graduate School of Engineering, Tohoku University, Sendai 980-8579, Japan. \\ 4Department of Materials Science and Engineering, Norwegian University of Science and Technology, Trondheim 7491, \\ Norway.

\begin{abstract}
Molten inorganic salts containing solid nanoparticles with a stable and uniform dispersion have attracted great attention as efficient heat transfer and storage materials ${ }^{1,2}$ and for catalysis for chemical reactions $s^{3-5}$. Electrophoretic deposition in molten inorganic salts containing nanoparticles, have not been reported in the literature, compared with the related wide investigations in aqueous and organic suspensions ${ }^{6,7}$. Here we report the possibility of electrophoretic deposition of nanoparticles in high-temperature molten salts. In molten fluorides and chlorides, cell voltages of 1.2-1.5 V below the decomposition voltage of the electrolytes, were applied to perform the electrophoretic deposition of nanoparticles (e.g., $\mathrm{TiB}_{2}$ and $\mathrm{ZrB}_{2}$ ) on different cathode substrates, resulting in compact and adhesive coatings with high hardness. These findings should present opportunities to synthesize additional coatings and films via the proposed process.
\end{abstract}

KEYWORDS: electrophoretic deposition, molten inorganic salts, di-boride nanoparticles, di-boride coatings

Electrophoretic deposition (EPD) was discovered by Ruess in 1808, which has been investigated mostly in aqueous and organic solutions and widely used for synthesis of coatings and films ${ }^{8-10}$. However, the EPD of nanoparticles in molten inorganic salts has not been reported in the previous studies. In 1969 Kohn et al. prepared stable gold and silver sols in mixed nitrite melts $\left(100-300{ }^{\circ} \mathrm{C}\right)^{11}$. Nevertheless, they failed to conduct the electrophoretic plating of the gold colloids. Recently it has been reported that nanoparticles have been found to form stable colloids in molten halides and cyanides $\left(90-300{ }^{\circ} \mathrm{C}\right)^{12-15}$. Thus, we are curious about that if an external cell voltage (below the decomposition cell voltage of the electrolytes) is applied on these systems such as molten halides, could the EPD of nanoparticles happen? Therefore, in this paper the EPD of ceramic di-boride nanoparticles in molten halides are carried out.

The EPD of $\mathrm{TiB}_{2}$ nanoparticles was firstly explored in molten $\mathrm{NaF}_{-}-\mathrm{AlF}_{3}(61: 39 \mathrm{~mol})$ system at a temperature of $980{ }^{\circ} \mathrm{C}$. $\mathrm{TiB}_{2}$ nanoparticles (with a mean size of $50 \mathrm{~nm}$ ) were added into this melt (with a content of $20 \mathrm{~g} / \mathrm{L}$ ), contained in a graphite crucible (Fig. 1a). A graphite anode and a molybdenum cathode were placed vertically, with a constant cell voltage of $1.2 \mathrm{~V}$ imposed between them for $1 \mathrm{~h}$, to perform the EPD. After the deposition was terminated, the electrophoretic plated cathode was lifted and removed from the cell (see the Methods section for experimental details). 
a

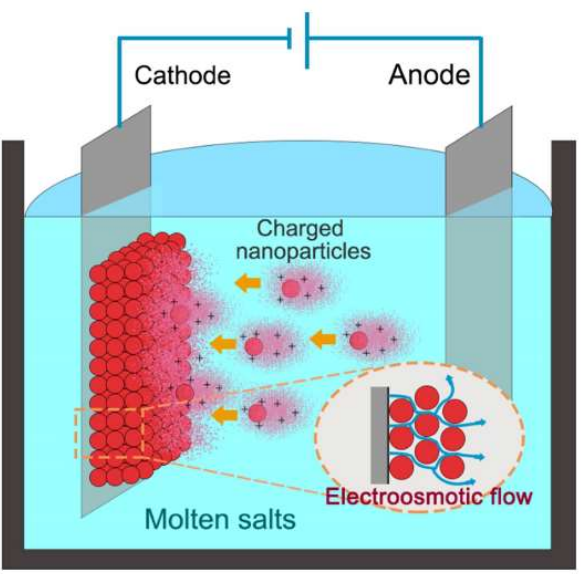

C

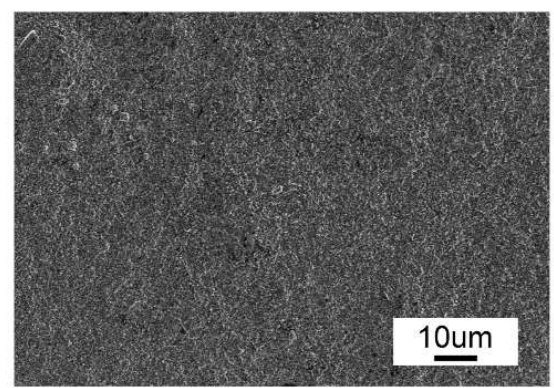

d

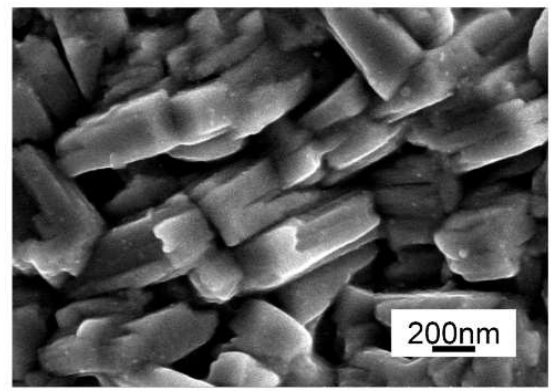

e

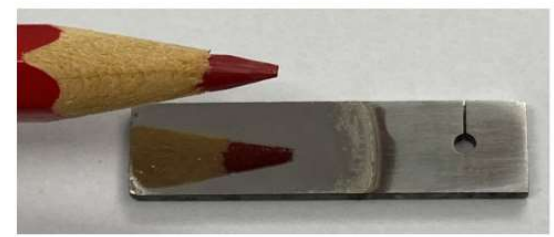

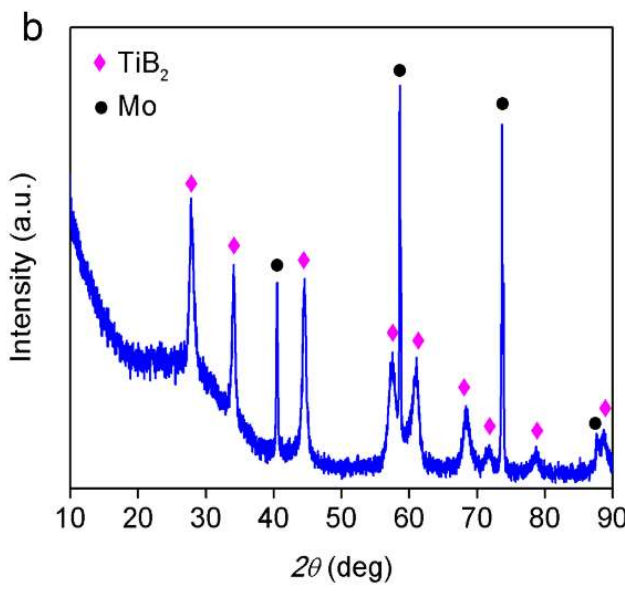

f
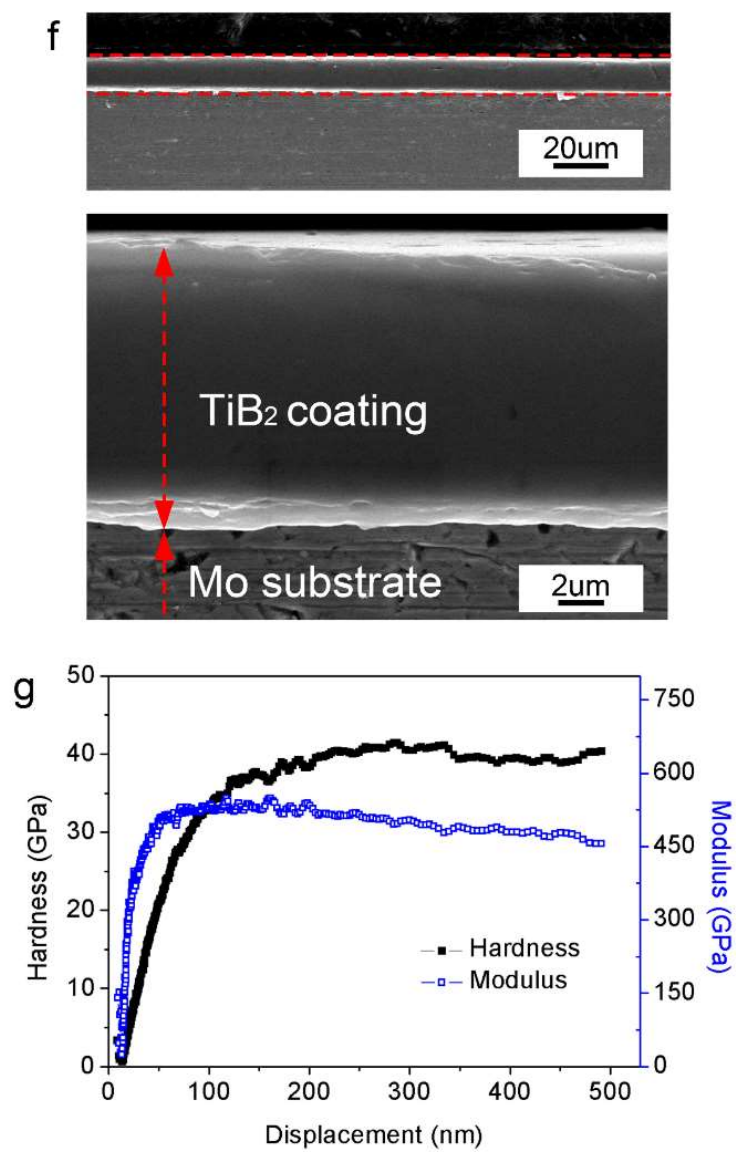

Figure $1 \mathbf{a}$, Schematic of electrophoretic deposition (EPD) in molten salts. $\mathbf{b}$, X-ray diffraction (XRD) pattern of the deposited coating on a molybdenum substrate in $\mathrm{TiB}_{2}$ nanoparticle-containing molten $\mathrm{NaF}_{-\mathrm{AlF}_{3}}$ (61:39 mol) system under a potentiostatic mode $(1.2 \mathrm{~V})$ at a temperature of $980{ }^{\circ} \mathrm{C}$. c-e, Scanning electron microscopy (SEM) images (c,d) and photograph (e) (polished) (note the reflection of the pencil) of $\mathrm{TiB}_{2}$ coating. $\mathbf{f}$, Micrographs of the cross-section of $\mathrm{TiB}_{2}$ coating. $\mathbf{g}$, The dependence of indentation hardness and elastic modulus on the indentation depth for the $\mathrm{TiB}_{2}$ coating.

The deposit on the molybdenum cathode was analyzed by X-ray diffraction (XRD) to be determined as a TiB 2 coating (Fig. 1b). The surface morphology of $\mathrm{TiB}_{2}$ coating was characterized by scanning electron microscopy (SEM) (Fig.1c), 
showing a flat appearance. The coating was ground by 400 \# SiC sandpaper, then exhibited a similarly metallic luster (Fig.1e). The cross-section of $\mathrm{TiB}_{2}$ coating as demonstrated in Fig. 1f, is revealing a flat, compact and adhesive layer, with a thickness of around $12 \mu \mathrm{m}$. Fig. $1 \mathrm{~g}$ shows the dependence of hardness and elastic modulus of the $\mathrm{TiB}_{2}$ coating on the indentation depth, with a maximum indentation depth of $500 \mathrm{~nm}$. After $\sim 150 \mathrm{~nm}$, the hardness and modulus remain relatively unchanged with the increase of indentation depth. Hardness of $\sim 40 \mathrm{GPa}$ and elastic modulus of $\sim 500 \mathrm{GPa}$ are obtained (compared with the reported values of 25-35 GPa for hardness and 500-560 GPa for elastic modulus for $\mathrm{TiB}_{2}{ }^{14}$ ). From these findings, it is concluded that the EPD of $\mathrm{TiB}_{2}$ nanoparticles has been successfully achieved in molten fluorides, yielding a coherent $\mathrm{TiB}_{2}$ coating with high hardness.

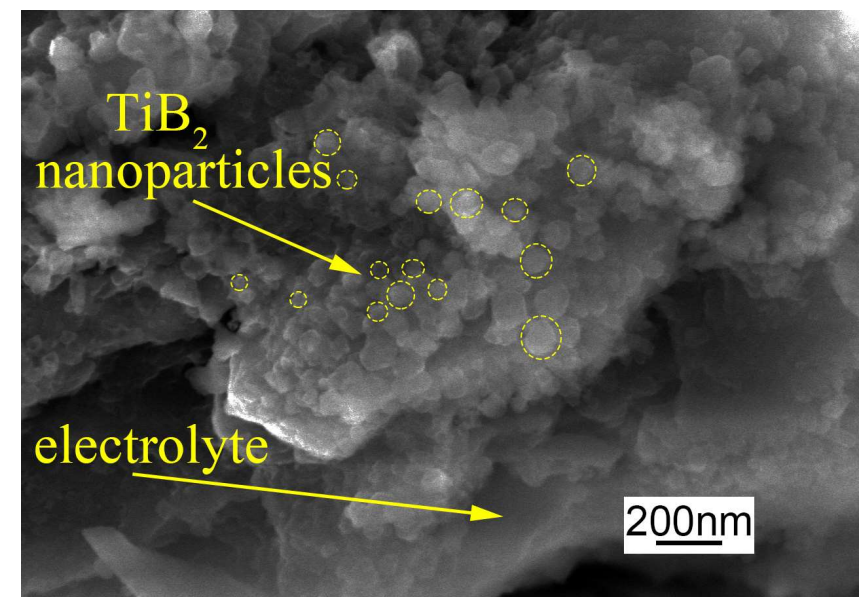

Figure 2 Micromorphology of quenched sample of $\mathrm{TiB}_{2}$ nanoparticle-containing melt located in the upper part of molten fluorides with the addition of $\mathrm{TiB}_{2}$ nanoparticles $5 \mathrm{~h}$ before.

In order to figure out the suspension state of added $\mathrm{TiB}_{2}$ nanoparticles in the above melt, we analyzed the local nanoparticles-containing electrolyte. We sampled the upper part of molten $\mathrm{NaF}_{-} \mathrm{AlF}_{3}$ salts with the introduction of $\mathrm{TiB}_{2}$ nanoparticles $5 \mathrm{~h}$ before, cooled it down to room temperature quickly and characterized it by SEM (Fig. 2). It was found that $\mathrm{TiB}_{2}$ nanoparticles still existed in the sampled solidified $\mathrm{NaF}_{-} \mathrm{AlF}_{3}$, which proves the stable suspension of $\mathrm{TiB}_{2}$ in the molten fluorides for at least $5 \mathrm{~h}$. Therefore, the achievement of the stable suspension in molten salts and the EPD on the cathode indicates the formation of stable and positively charged $\mathrm{TiB}_{2}$ colloids in molten $\mathrm{NaF}_{-} \mathrm{AlF}_{3}$ indirectly.

It is noted that a dense $\mathrm{TiB}_{2}$ coating, without any inclusion of residual fluoride electrolyte, has been fabricated at only $980{ }^{\circ} \mathrm{C}$. Actually, powdery $\mathrm{TiB}_{2}$, with a melting point up to $3225{ }^{\circ} \mathrm{C}$, is difficult to be sintered to full density ${ }^{16,17}$. For example, Rabiezadeh et al. made attempts to sinter $\mathrm{TiB}_{2}$ nanoparticles without sintering additives under hot press at $1700{ }^{\circ} \mathrm{C}$ for $2 \mathrm{~h}$ and obtained $92 \%$ of the theoretical density ${ }^{18}$. In the present paper the preparation of dense $\mathrm{TiB}_{2}$ coating is probably due to the occurrence of electroosmotic motion of molten salts during the EPD of $\mathrm{TiB}_{2}$ nanoparticles. As shown in Fig.1a, as $\mathrm{TiB}_{2}$ nanoparticles migrates to the cathode, the electroosmotic flow of molten salts inside the not yet densified $\mathrm{TiB}_{2}$ layer is driven away from it. In fact, it has been reported that during EPD in aqueous suspensions, the nanoparticles rearrangement is accelerated via the electroosmotic flow, leading to higher packing rates of nanoparticles $^{19-21}$. It has also been suggested that for liquid assisted flash sintering, the existence of electroosmotic driven flow benefits the densification of sintering of nanoparticles ${ }^{22}$. In this paper, from the SEM image of the surface morphology (with higher magnification) of $\mathrm{TiB}_{2}$ coating (Fig.1d), large nanoplates consisting of original nanoparticles were observed, which represents an intermediate state during the growth of $\mathrm{TiB}_{2}$ nanoparticles. It seems that during the EPD, the $E P D e d \mathrm{TiB}_{2}$ nanoparticles on the surface of the cathode gather and grow up to form these large nanoplates with a thickness of 100-200 nm and a length of $\sim 500 \mathrm{~nm}$, with the assistance of electroosmotic flow. Finally, these nanoplates continuously grow up to collect each other to form the dense $\mathrm{TiB}_{2}$ coating. Summarily, the occurrence of EPD of nanoparticles is accompanied by the existence of electroosmotic driven flow of molten salts, which probably promotes the forming of dense coating at a high temperature. These results also provide a novel and substantial addition to electrokinetic phenomena in colloid science. 
In the same molten salts at $980{ }^{\circ} \mathrm{C}$, a graphite cathode was employed to perform the electrophoretic deposition of $\mathrm{TiB}_{2}$ nanoparticles (with a content of $70 \mathrm{~g} / \mathrm{L}$ ), via the similar procedures as the above description. In Fig. 3 a, the photo and micromorphology of the EPDed coating are presented. An apparent coating was observed on the graphite substrate and the surface micromorphology seemed relatively flat. Fig. 3 b,c shows the fractured cross-section and XRD result of the coating, which was proved to be a flat, compact and adhesive $\mathrm{TiB}_{2}$ coating with a thickness of around $50 \mu \mathrm{m}$. Its micro-hardness was measured by a Vickers micro-hardness tester, giving an average value of $3500 \mathrm{HV}_{0.1}$. These results indicate that the successful electrophoretic deposition of $\mathrm{TiB}_{2}$ nanoparticle on a graphite substrate in molten fluorides has been accomplished, which could lead to the possibility of producing wettable $\mathrm{TiB}_{2}$-coated carbon cathode for aluminum electrolysis ${ }^{23}$.

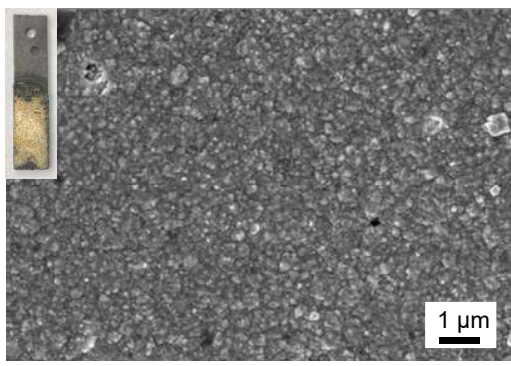

b

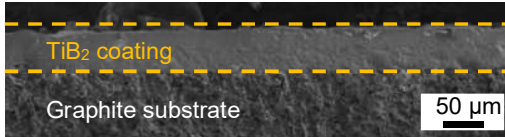

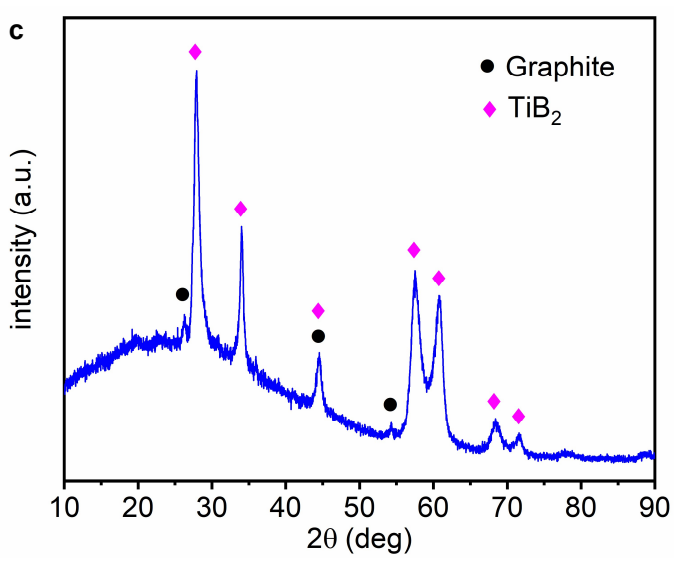

Figure 3 a, SEM image and photograph (top-left inset) of the EPDed coating on a graphite substrate in TiB nanoparticle-containing molten $\mathrm{NaF}_{-}-\mathrm{AlF}_{3}(61: 39 \mathrm{~mol})$ system under potentiostatic mode $(1.2 \mathrm{~V})$ for $1 \mathrm{~h}$ at a temperature of $980{ }^{\circ} \mathrm{C}$. b,c, Micrograph of the cross-section (b) and XRD pattern (c) of the $\mathrm{TiB}_{2}$ coating.

Besides molten fluorides, molten $\mathrm{NaCl}-\mathrm{KCl}-\mathrm{AlCl}_{3}(45: 45: 10 \mathrm{~mol})$ system at $710{ }^{\circ} \mathrm{C}$ was also applied to conduct the EPD of $\mathrm{ZrB}_{2}$ nanoparticles (with a mean size of $50 \mathrm{~nm}$ ), with the similar cell shown in Fig. 1a. A graphite anode and a graphite cathode were employed, with an applied cell voltage of $1.5 \mathrm{~V}$ for $1 \mathrm{~h}$. After the deposition, the coated cathode was removed, cleaned and dried (see the experimental details in Methods section). 
a

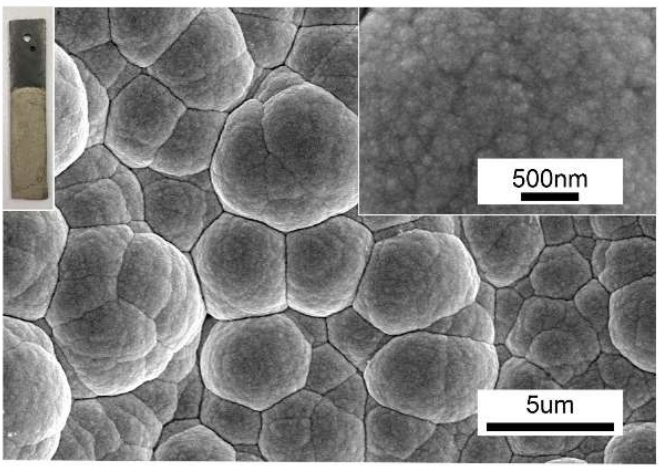

C

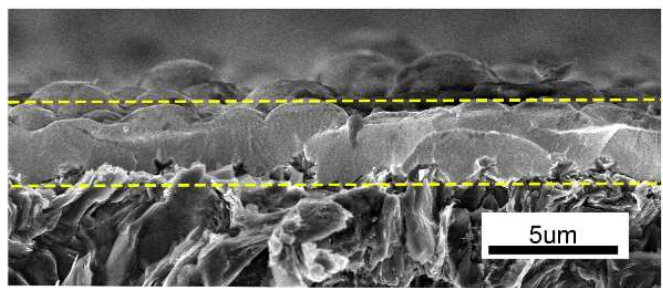

e

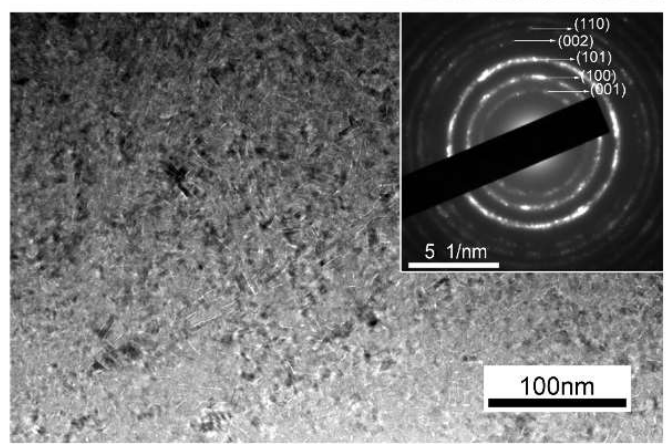

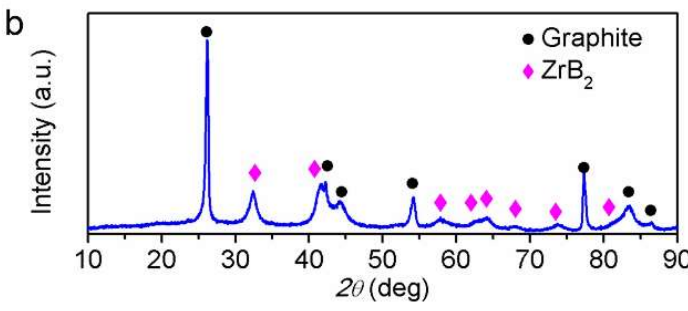

d

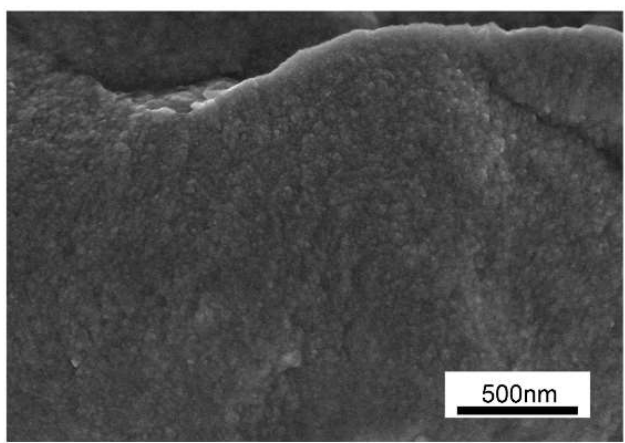

f

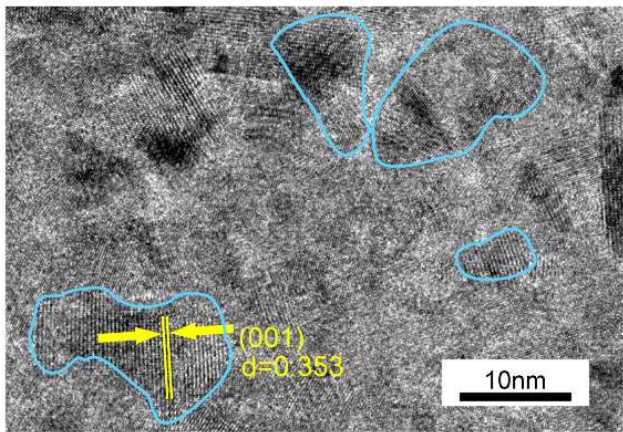

Figure 4 a, SEM images and photograph (top-left inset) of deposited coating on a graphite substrate under a potentiostatic mode $(1.5 \mathrm{~V})$ in molten $\mathrm{NaCl}-\mathrm{KCl}-\mathrm{AlCl}_{3}(45: 45: 10 \mathrm{~mol})$ system at a temperature of $710{ }^{\circ} \mathrm{C}$. b-d, XRD pattern (b) and micrographs of the fractured cross-section (c,d) of $\mathrm{ZrB}_{2}$ coating. e, Typical transmission electron microscopy (TEM) image and its selected area electron diffraction (SAED) pattern (top-right inset) of $\mathrm{ZrB}_{2}$ coating. f, Lattice-resolved high resolution TEM (HRTEM) image.

The electrophoretic plated coating, exhibiting a similarly metallic appearance (top-left inset of Fig. 4a), on the graphite substrate was characterized by SEM (Fig. 4a). It was found that the coating was made up of micro-particles, which consisted of nanoparticles as observed under higher magnification. The XRD pattern (Fig. 4b) with broad diffraction peaks proved that it was a $\mathrm{ZrB}_{2}$ coating with possible nanocrystal feature. The fractured cross-section of the $\mathrm{ZrB}_{2}$ layer was observed by SEM (Fig. 4c,d). It is dense and adhesive, with a thickness of approximately $2 \mu \mathrm{m}$, over the whole cross-section showing a nanostructure under higher magnification. Fig. 4e shows the transmission electron microscopy (TEM) image and the selected area electron diffraction (SAED) pattern (top-right inset of Fig. 4e) of the sample. SAED pattern included continuous but rather broad diffraction rings, which indicated polycrystalline microstructure with possible nanocrystal structure of the $\mathrm{ZrB}_{2}$ coating. High resolution TEM (HRTEM) image is shown in Fig. 4f, which confirmed the presence of nanocrystallites. From the original nanoparticles to nanocrystal and compact $\mathrm{ZrB}_{2}$ coating, the maintaining of the nanocrystal structure reveals the possibility of assembling nanoparticles by EPD in molten chlorides. In addition, the hardness and the elastic modulus of the $\mathrm{ZrB}_{2}$ coating was assessed with a nanoindenter, giving the values of $20 \mathrm{GPa}$ and $146 \mathrm{GPa}$, respectively. Therefore, the EPD of $\mathrm{ZrB}_{2}$ nanoparticles has been successfully conducted in molten chlorides, resulting in a dense and adhesive $\mathrm{ZrB}_{2}$ coating with a nanocrystal structure.

Compared with that in aqueous or organic solutions, EPD in high-temperature molten salts has the advantages as 
follows. Firstly, the required cell voltages of 1.2-1.5 V in high-temperature molten salts are far below the values of 20-300 V generally applied in aqueous or organic solutions ${ }^{7}$. Secondly, EPD in high-temperature molten salts results in a dense and adhesive coating in one step. While in aqueous or organic solutions, the resulting deposits with high porosity, low density and poor adhesion generally need further drying and sintering, however, resulting in cracking, which is difficult to be dealt with $^{7,24}$. It is our anticipation that the EPD of nanoparticles in molten inorganic salts should become an important method for synthesis of ceramic coatings and films.

In summary, for the first time the EPD of ceramic di-boride nanoparticles has been demonstrated in molten halides, resulting in dense and adhesive coatings with high hardness. These findings could open opportunities to fabricate coatings and films by the proposed novel process. Molten inorganic salts represent a very attractive class of solvents (including halides, sulfides, nitrates and carbonates) for the stable dispersion and synthesis of nanomaterials (e.g., borides, oxides, carbides and nitrides) ${ }^{25-27}$. It may be assumed that the EPD can be applied to a wider range of nanoparticles and in other molten salts systems, possibly resulting in preparing more types of coatings and films with desired properties. Furthermore, if the EPD is employed for in-situ synthetic nanoparticles in molten inorganic salts, it is likely to result in additional new phenomena. 


\section{Note}

The authors declare no competing financial interests.

Acknowledgements

This work was supported by the National Natural Science Foundation of China (51404001). 


\section{References}

1. Muñoz-Sánchez, B., Nieto-Maestre, J., Iparraguirre-Torres, I., García-Romero, A. \& Sala-Lizarraga, J.M. Molten salt-based nanofluids as efficient heat transfer and storage materials at high temperatures. An overview of the literature. Renew. Sust. Energ. Rev. 82, 3924-3945 (2018).

2. Tiznobaik, H. \& Shin, D. Enhanced specific heat capacity of high-temperature molten salt-based nanofluids. Int. J. Heat Mass Transf. 57, 542-548 (2013).

3. Licht, $\mathrm{S}$. et al. Ammonia synthesis by $\mathrm{N}_{2}$ and steam electrolysis in molten hydroxide suspensions of nanoscale $\mathrm{Fe}_{2} \mathrm{O}_{3}$. Science 345, 637-640 (2014).

4. Harada, T., Brown, P. \& Hatton, T.A. Nonvolatile colloidal dispersion of $\mathrm{MgO}$ nanoparticles in molten salts for continuous $\mathrm{CO}_{2}$ capture at intermediate temperatures. ACS Sustain. Chem. Eng. 7, 7979-7986 (2019).

5. Tangeysh, B., Palmer, C., Metiu, H., Gordon, M.J. \& McFarland, E.W. High-temperature heterogeneous catalysis in platinum nanoparticle-molten salt suspensions. Catal. Sci. Technol. 10, 625-629 (2020).

6. Mohamed, A.M. \& Golden, T.G. Electrodeposition of composite materials, (BoD-Books on Demand, 2016).

7. Dickerson, J.H. \& Boccaccini, A.R. Electrophoretic deposition of nanomaterials, (Springer, 2011).

8. Corni, I., Ryan, M.P. \& Boccaccini, A.R. Electrophoretic deposition: from traditional ceramics to nanotechnology. J. Eur. Ceram. Soc. 28, 1353-1367 (2008).

9. $\mathrm{Wu}, \mathrm{Y} ., \mathrm{Li}, \mathrm{J} .$, Tanaka, H., Kuwabara, M. Preparation of nano-structured $\mathrm{BaTiO}_{3}$ thin film by electrophoretic deposition and its characterization. J. Eur. Ceram. Soc. 25, 2041-2044 (2005).

10. Farrokhi-Rad, M., Mohammadalipour, M., Shahrabi, T. Electrophoretically deposited halloysite nanotubes coating as the adsorbent for the removal of methylene blue from aqueous solution. J. Eur. Ceram. Soc. 38, 3650-3659 (2018).

11. Kohn, H.W. \& Willmarth, T.E. Metallic colloids in molten salts. Science 163, 924-925 (1969).

12. Zhang, H., Dasbiswas, K., Ludwig, N.B., Han, G. \& Talapin, D.V. Stable colloids in molten inorganic salts. Nature 542, 328-331 (2017).

13. Srivastava, V. et al. Colloidal chemistry in colten salts: synthesis of luminescent $\ln _{(1-x)} G a_{x} P$ and $\ln _{(1-x)} G a_{x} A s$ quantum dots. J. Am. Chem. Soc. 140, 12144-12151 (2018).

14. Navarrete, N., Gimeno-Furió, A., Forner-Escrig, J., Juliá, J.E. \& Mondragón, R. Colloidal stability of molten saltbased nanofluids: Dynamic Light Scattering tests at high temperature conditions. Powder Technol. 352, 1-10 (2019).

15. Kamysbayev, V. et al. Nanocrystals in molten salts and ionic liquids: experimental observation of ionic correlations extending beyond the Debye length. ACS nano 13, 5760-5770 (2019).

16. Golla, B.R., Mukhopadhyay, A., Basu, B. \& Thimmappa, S.K. Review on ultra-high temperature boride ceramics. Prog. Mater. Sci. 111, 100651 (2020).

17. Baik, S. \& Becher, P.F. Effect of oxygen contamination on densification of TiB 2 . J. Am. Ceram. Soc. 70, 527-530 (1987).

18. Rabiezadeh, A., Hadian, A.M. \& Ataie, A. Synthesis and sintering of $\mathrm{TiB}_{2}$ nanoparticles. Ceram. Int. 40, 15775-15782 (2014).

19. Neirinck, B., Van der Biest, O. \& Vleugels, J. A current opinion on electrophoretic deposition in pulsed and alternating fields. J. Phys. Chem. B 117, 1516-1526 (2013).

20. Yang, S., Cai, W., Liu, G. \& Zeng, H. From nanoparticles to nanoplates: preferential oriented connection of Ag colloids during electrophoretic deposition. J. Phys. Chem. C 113, 7692-7696 (2009).

21. Xue, L., Kajiyoshi, K. \& Yan, Y. Preparation of highly oriented titania nanosheet thin films by electrophoretic deposition. Thin Solid Films 518, 10-15 (2009)

22. Rachman, C. On the kinetics of liquid-assisted densification during flash sintering of ceramic nanoparticles. Scr. Mater. 158, 88-90 (2019).

23. $\mathrm{Li}, \mathrm{J}$., Lü, X., Lai, Y., Li, Q. \& Liu, Y. Research progress in $\mathrm{TiB}_{2}$ wettable cathode for aluminum reduction. JOM 60 32-37 (2008).

24. Pikalova, E.Y. \& Kalinina, E. Electrophoretic deposition in the solid oxide fuel cell technology: fundamentals and recent advances. Renew. Sust. Energ. Rev. 116, 109440 (2019).

25. Dias, E.T. et al. Radiation-assisted formation of metal nanoparticles in molten salts. J. Phys. Chem. Lett. 12, 157-164 (2020).

26. Dash, A., Vassen, R., Guillon, O. \& Gonzalez-Julian, J. Molten salt shielded synthesis of oxidation prone materials in air. Nat. Mater. 18, 465-470 (2019). 
27. Gupta, S.K. \& Mao, Y. A review on molten salt synthesis of metal oxide nanomaterials: status, opportunity, and challenge. Prog. Mater. Sci., https://doi.org/10.1016/j.pmatsci.2020.100734. 


\section{Methods}

Nanoparticle-containing solid salts preparation. Two types of solid salts (i.e., fluorides and chlorides) were employed in this paper. The processes for manufacturing mixtures of solid salts and nanoparticles are the same, with the schematic shown in Fig. 5. The mixed solid $\mathrm{NaF}\left(>99 \%\right.$, Aladdin) and $\mathrm{AlF}_{3}(>98 \%$, Guanfu) or $\mathrm{NaCl}(>99 \%$, Sinopharm) and $\mathrm{KCl}$ (>99\%, Sinopharm) were milled with 316 stainless milling balls $(\varphi 1 \mathrm{~mm}: \varphi 3 \mathrm{~mm}=3: 2$ mass) for $3 \mathrm{~h}$ in a planetary ball mill (HLXPM- $\varphi 10 X 4$, Hengle), with both revolution and rotation speeds of 120 r.p.m. The milled solid salts were blended with nanoparticles ( $\mathrm{TiB}_{2}$ (mean size $50 \mathrm{~nm}, 99 \%$, ChaoWei) and $\mathrm{ZrB} 2$ (mean size $50 \mathrm{~nm}, 99 \%$, ChaoWei)), in a weight ratio of $1: 1$, followed by ultrasonic dispersion in acetone at $100 \mathrm{kHz}$ for $2 \mathrm{~h}$. Finally, the mixture in a slurry form was dried in a vacuum drying oven at $120^{\circ} \mathrm{C}$ for $1 \mathrm{~h}$.

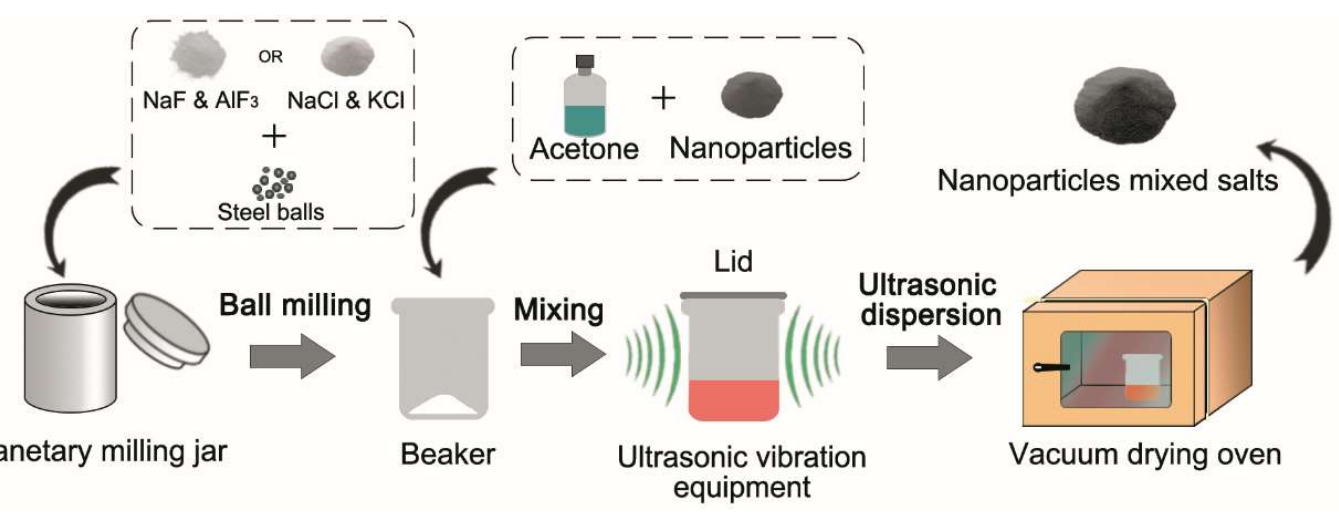

Figure 5 Stepwise schematic of preparation of nanoparticles-containing solid salts.

Electrophoretic deposition process in molten salts. For all the experiments of EPD, the procedures of preparation of high-temperature molten salts containing nanoparticles are as follows. The mixture of $\mathrm{NaF}$ and $\mathrm{AlF}_{3}(61: 39 \mathrm{~mol})$ or $\mathrm{NaCl}$, $\mathrm{KCl}$ and $\mathrm{AlCl}_{3}(>99 \%$, Aladdin) $(45: 45: 10 \mathrm{~mol})$ were introduced to a graphite crucible, which was placed in an electric resistance furnace, heated up to temperatures of $980{ }^{\circ} \mathrm{C}$ and $710{ }^{\circ} \mathrm{C}$, respectively. After the mixture was melted, the prepared solid salts containing nanoparticles mentioned in the above section were added to the molten salts, resulting in molten salts including nanoparticles with a required content. The resulting molten mixture stabilized for $10-20 \mathrm{~min}$, followed by the subsequent process.

As shown in Fig. 1a, the high-temperature molten salts including nanoparticles were contained in a crucible. A molybdenum or graphite cathode $\left(4^{\star} 1 * 25 \mathrm{~mm}\right.$ or $\left.8^{*} 3^{\star} 30 \mathrm{~mm}\right)$, with an immersion depth of $10-20 \mathrm{~mm}$, and a graphite anode with an immersion depth of $15-20 \mathrm{~mm}$ were placed in the cell. Before use the cathodes were ground by successively finer $\mathrm{SiC}$ sandpaper, followed by an ultrasonic cleaning in acetone and dried for use. In molten fluorides and chlorides, the temperature was controlled at $980{ }^{\circ} \mathrm{C}$ and $710{ }^{\circ} \mathrm{C}$, respectively. Pre-electrolysis under $1.5 \mathrm{~V}$ cell voltage for $1 \mathrm{~h}$ was needed to remove some impurities. The EPD was under a constant voltage mode, ranging from 1.2-1.5 V for $1 \mathrm{~h}$. A DC power supply (HLR-3660D, Henghui) was used to perform the potentiostatic control. All the EPD were performed in an argon atmosphere.

After the EPD was terminated, the coated cathode was removed from the cell. After the coated cathode was withdrawn from the molten chlorides, it was immersed in deionized water for $1 \mathrm{~h}$ to remove the solid chloride salt residues, in acetone for $5 \mathrm{~min}$ to remove the water, followed by drying. After the coated cathode was withdrawn from the molten fluorides, it was soaked in molten $\mathrm{NaCl}-\mathrm{KCl}$ at $710^{\circ} \mathrm{C}$ for $5 \mathrm{~min}$ to remove the solid fluoride salt residues and the subsequent processing was the same as for coated cathodes prepared in molten chlorides.

The coated molybdenum was embedded in epoxy resin at room temperature and ground by successively finer SiC sandpaper, followed by polishing using diamond abrasion paste, resulting in the sample of cross-section of $\mathrm{TiB}_{2}$ coating (Fig. 1f). The coated graphite was broken down to obtain the fractured cross-section of the $\mathrm{TiB}_{2}$ and $\mathrm{ZrB}_{2}$ coatings (Fig. 3b and $4 \mathrm{c}, \mathrm{d})$.

Characterization. The EPDed coatings were examined using a SEM (Regulus 8220, HITACHI), TEM (JEM-2100, JEOL) and XRD (Smart Lab, Rigaku) to analyze their micromorphology, microstructure and phase composition. TEM samples were prepared using a precision ion polishing system (Model 691, Gatan) for Fig. 4 e,f.

The EPDed coatings were ground by successively finer SiC sandpaper to obtain a smooth surface for nanoindentation tests. Their hardness and elastic modulus were assessed by a nanoindenter (Nano Indenter G200, Agilent). Six indentations tests on various parts of each coating were conducted to ensure the reliability. 
For thick coatings, the surface micro-hardness was measured with a Vickers micro-hardness tester (MH-5LD, Hengyi) using a load of $100 \mathrm{gf}$. 


\section{Figures}

a

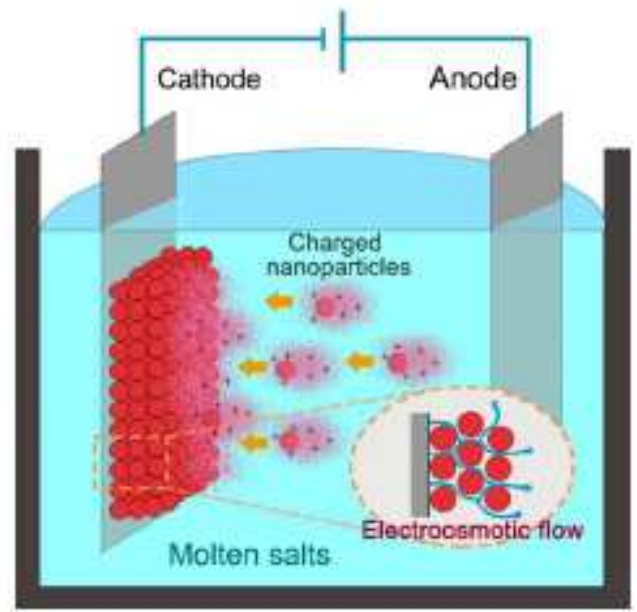

C

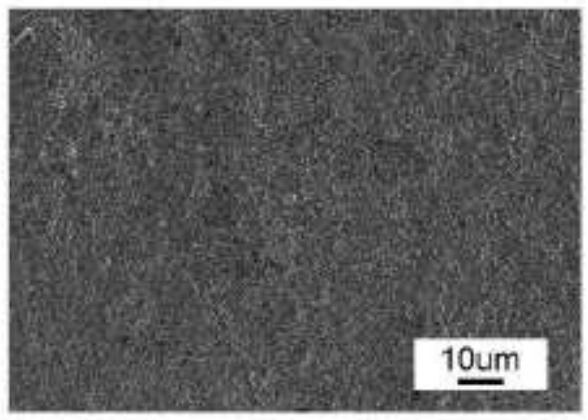

d

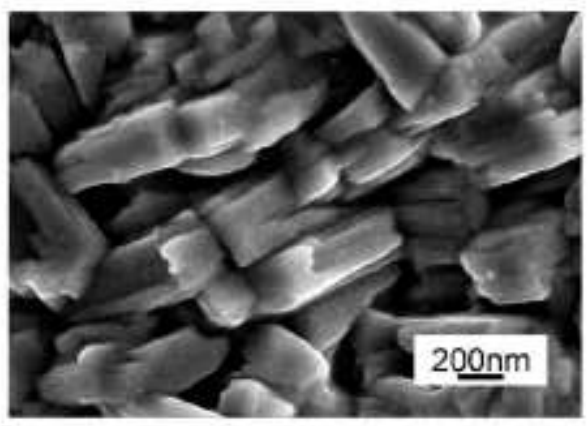

e

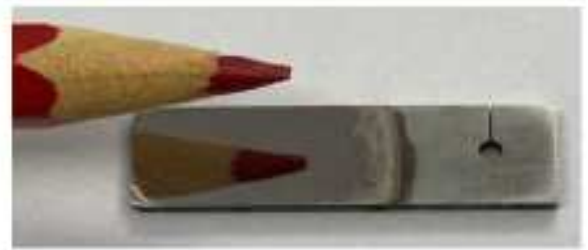

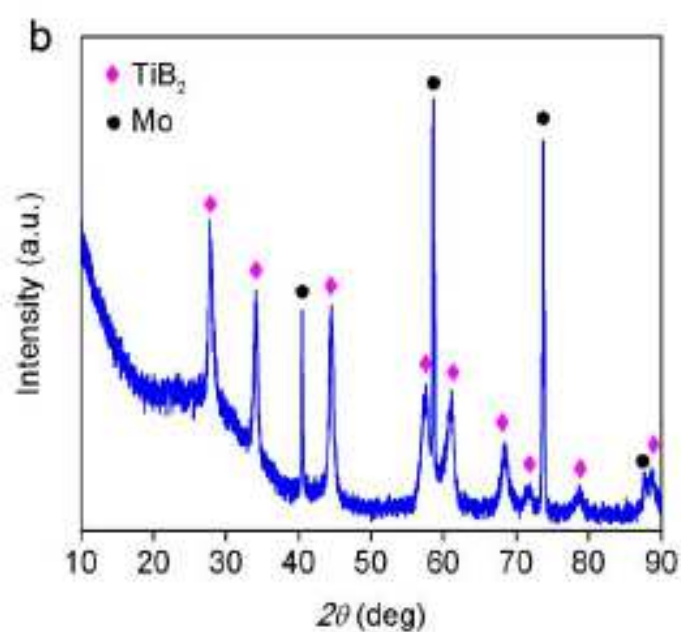

f
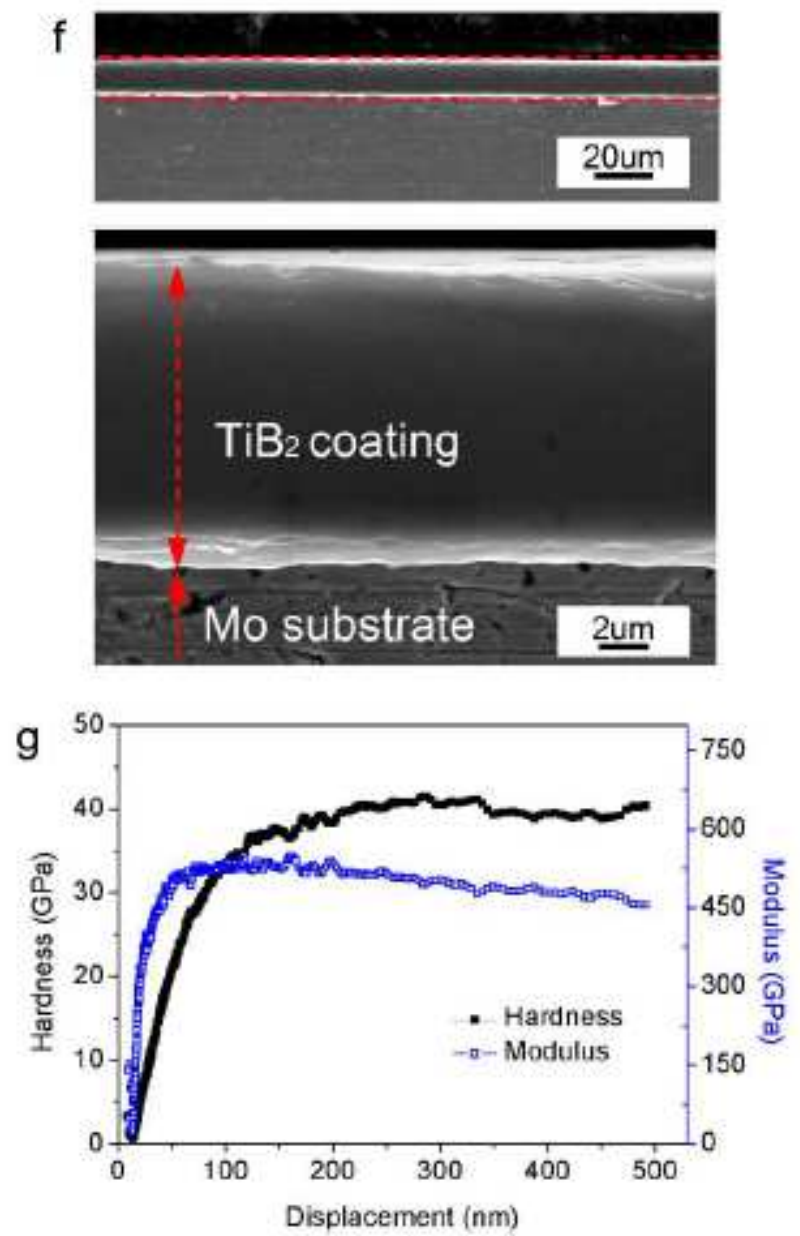

\section{Figure 1}

a, Schematic of electrophoretic deposition (EPD) in molten salts. b, X-ray diffraction (XRD) pattern of the deposited coating on a molybdenum substrate in TiB2 nanoparticle-containing molten NaF-AIF3 (61:39 mol) system under a potentiostatic mode (1.2 V) at a temperature of 980 \. c-e, Scanning electron 
microscopy (SEM) images (c,d) and photograph (e) (polished) (note the reflection of the pencil) of TiB2 coating. $\mathrm{f}$, Micrographs of the cross-section of TiB2 coating. $\mathrm{g}$, The dependence of indentation hardness and elastic modulus on the indentation depth for the TiB2 coating.

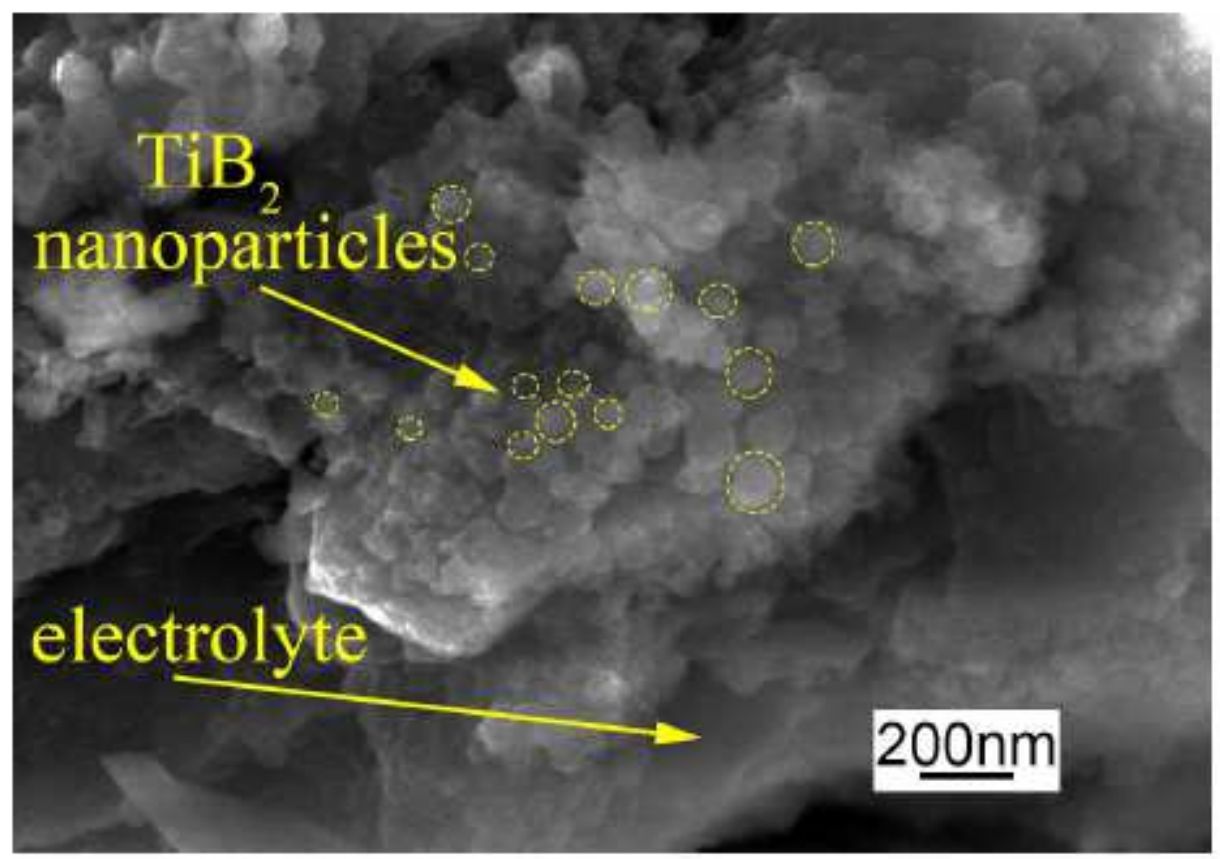

\section{Figure 2}

Micromorphology of quenched sample of TiB2 nanoparticle-containing melt located in the upper part of molten fluorides with the addition of TiB2 nanoparticles $5 \mathrm{~h}$ before.

a

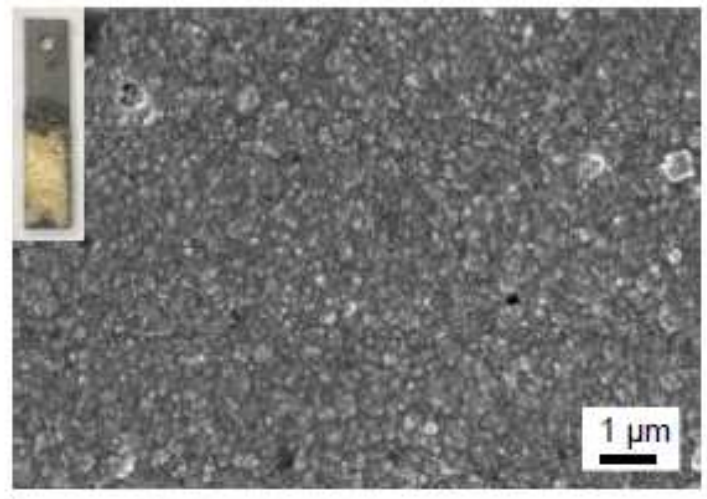

b

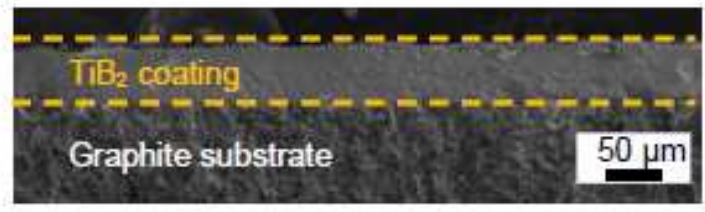

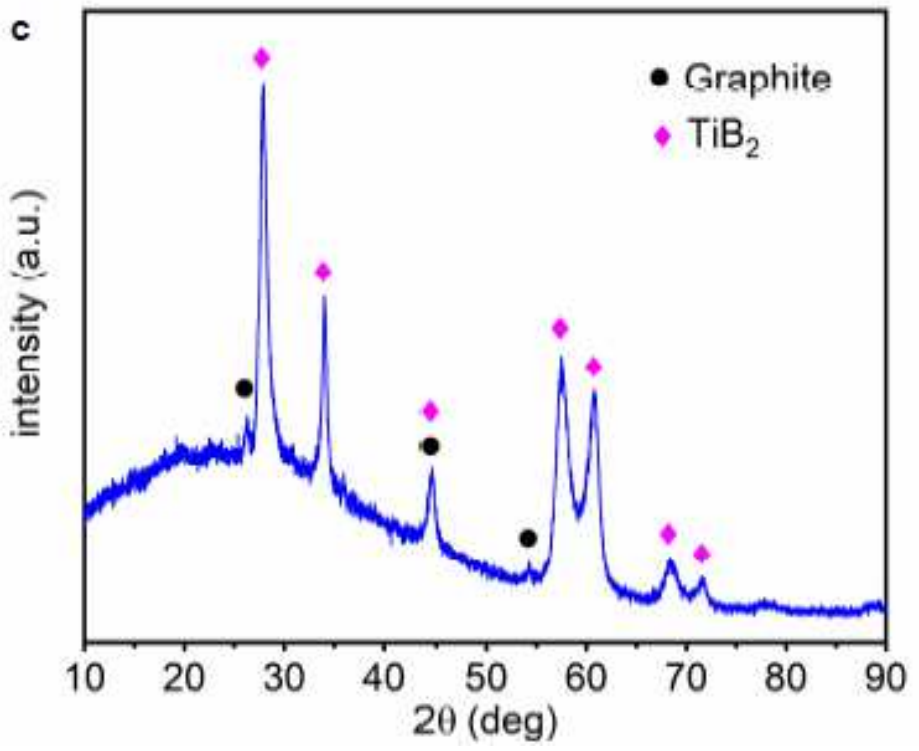

Figure 3

a, SEM image and photograph (top-left inset) of the EPDed coating on a graphite substrate in TiB2 nanoparticle-containing molten NaF-AlF3 $(61: 39 \mathrm{~mol})$ system under potentiostatic mode $(1.2 \mathrm{~V})$ for $1 \mathrm{~h}$ at 
a temperature of 980 \. b,c, Micrograph of the cross-section (b) and XRD pattern (c) of the TiB2 coating.

a

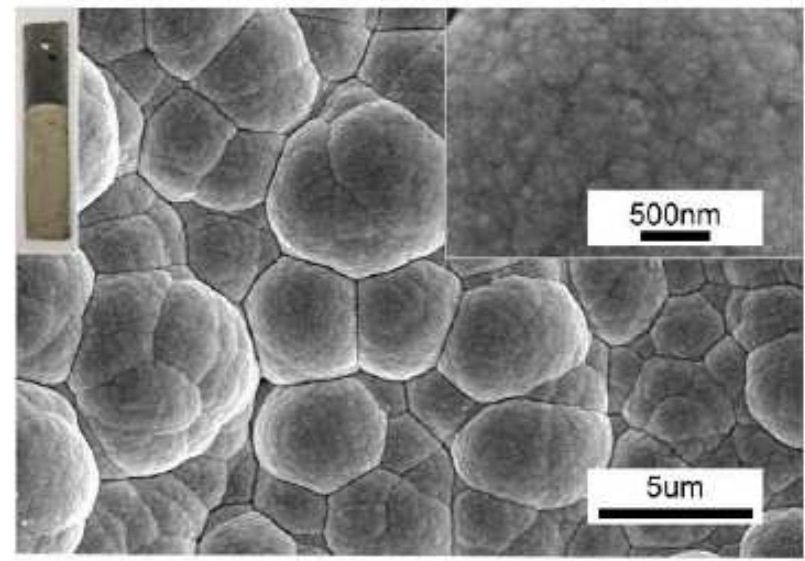

C

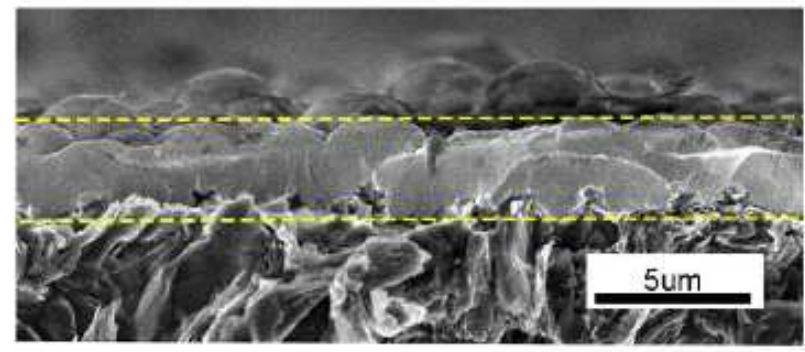

e

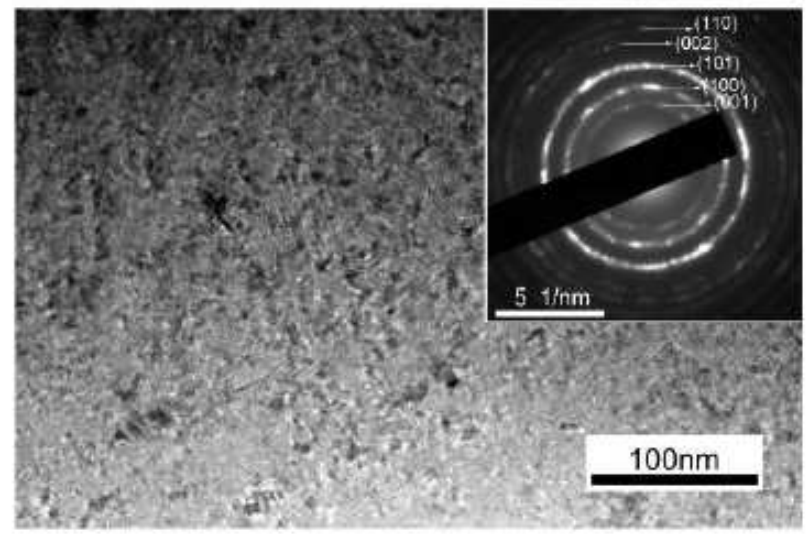

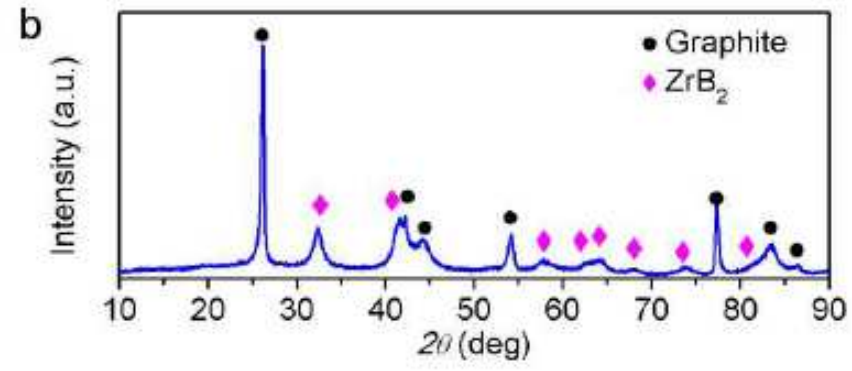

d

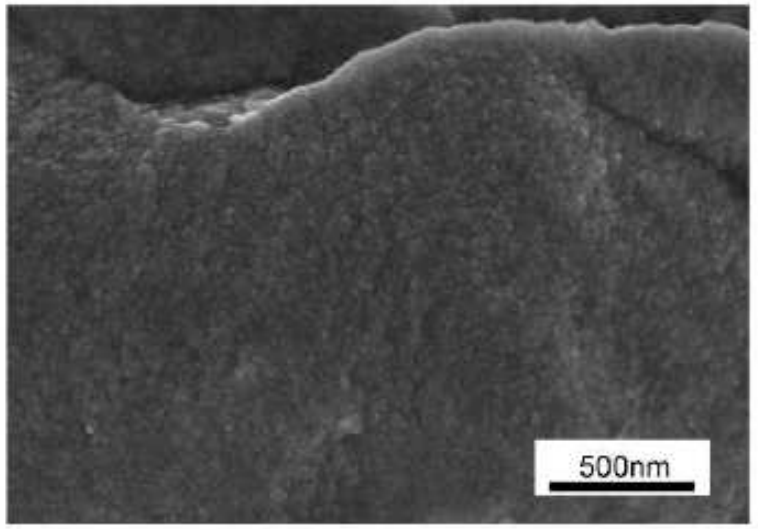

f

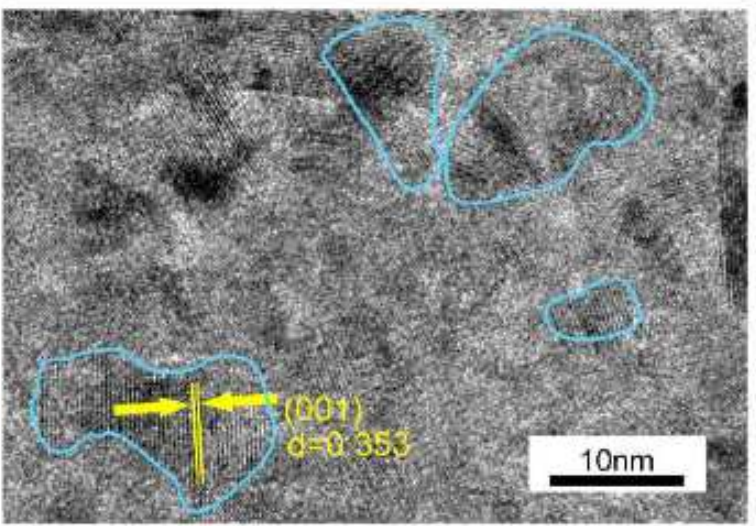

\section{Figure 4}

a, SEM images and photograph (top-left inset) of deposited coating on a graphite substrate under a potentiostatic mode $(1.5 \mathrm{~V})$ in molten $\mathrm{NaCl}-\mathrm{KCl}-\mathrm{AlCl} 3(45: 45: 10 \mathrm{~mol})$ system at a temperature of 710 ه. b$d$, XRD pattern (b) and micrographs of the fractured cross-section (c,d) of ZrB2 coating. e, Typical transmission electron microscopy (TEM) image and its selected area electron diffraction (SAED) pattern (top-right inset) of ZrB2 coating. f, Lattice-resolved high resolution TEM (HRTEM) image. 


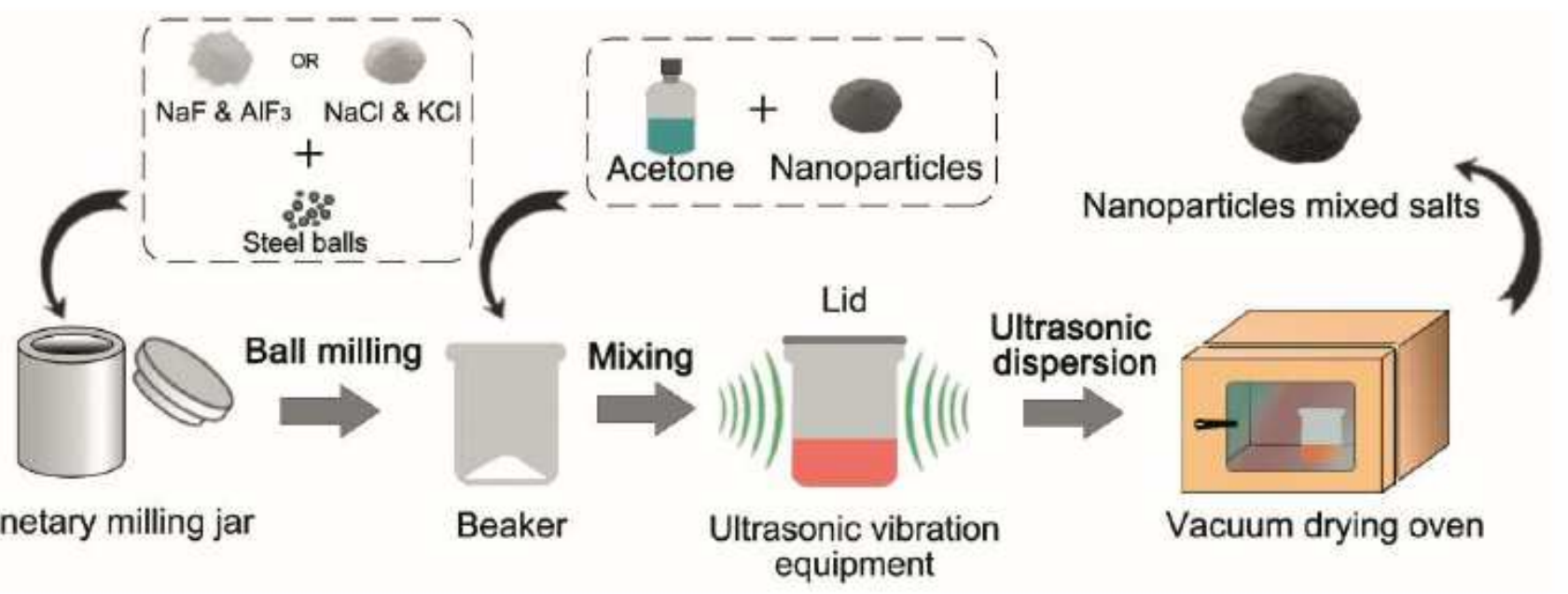

Figure 5

Stepwise schematic of preparation of nanoparticles-containing solid salts. 